\title{
Journal of Cardiovascular Magnetic

\section{Background offset error in pulmonary and aortic phase contrast flow imaging of 94 patients}

\author{
Annette L Dahl*, Peter D Gatehouse and Philip J Kilner
}

Address: The Royal Brompton Hospital, London, UK

* Corresponding author

from 13th Annual SCMR Scientific Sessions

Phoenix, AZ, USA. 2I-24 January 2010

Published: 21 January 2010

Journal of Cardiovascular Magnetic Resonance 20 10, I2(SuppI I):TI3 doi:I0.I I86/I532-429X-I2-SI-TI3

This abstract is available from: http://jcmr-online.com/content/I2/SI/TI3

(c) 2010 Dahl et al; licensee BioMed Central Ltd.

\begin{abstract}
Background
Velocity-encoding generates small eddy currents causing background offset errors (recognised as velocity of stationary tissue). Chernobelsky et al. (2007) assessed background offset correction on 10 volunteers, demonstrating that offset errors $\approx 1 \%$ of VENC can cause up to $25 \%$ errors during measurements. No larger studies have yet measured this error.
\end{abstract}

\section{Methods}

Patients were scanned at 1.5T (Siemens Avanto VB15, 12channel phased-array coil) with a retrospectively ECGgated, breath-hold flow sequence (turbo-factor 6, TR10/ TE2.3ms, $698 \mathrm{~Hz} /$ pixel, flip angle $25^{\circ}$, FOV $320-360 \mathrm{~mm}$, $1.3 \times 2.5 \mathrm{~mm}$ at $320 \mathrm{mmFOV}, 10 \mathrm{~mm}$ SLT, Maxwell-correction, no other background-correction, VENC 80-420 (avg.175) cm/s). Oblique aortic and/or pulmonary flow studies in 94 patients were reproduced using a stationary jelly-phantom, with the exact imaging parameters used invivo including individual ECG simulations. Throughplane flow was calculated (CMRtools, CVIS) by outlining the cross-sectioned vessel and adding volume flow over the cardiac cycle. The region of interest was copied onto the phantom image to find the background offset in $\mathrm{ml} /$ beat. During each scan the couch moved automatically to zero the head-foot ( $\mathrm{z}$-) location; this should always have placed the vessel of interest at $z=0$ but residual head-foot vessel locations were recorded. Correlations between the background offset and relevant study parameters were tested.

\section{Results and discussion}

Aortic and pulmonary flows showed average absolute offsets of $2.2 \mathrm{ml} /$ beat $(\mathrm{n}=87)$ and $3.9 \mathrm{ml} /$ beat $(\mathrm{n}=45)$, with largest absolute errors of $15 \mathrm{ml} /$ beat and $26 \mathrm{ml} /$ beat (Figure 1). No significant correlation between background offset error and overestimated VENC or vessel cross-sectional area was found. A weak association of offset error with the residual head-foot location of the vessel was apparent, consistent with the experience at several centers that a transverse slice is preferable for flow, because it is then easier to ensure the vessel is at $\mathrm{z}=0$. Careful consideration must also be taken when calculating phantom correction, as errors can be either subtracted or added onto vessel measurements, depending whether they are expressed as positive or negative values. Previous comparison of different MRI systems strongly suggests that this is not unique to the system and protocol used in this work. The clinical flow protocol evaluated in this work did not make full use of gradient performance.

\section{Conclusion}

In this protocol, uncorrected background offset error would have caused $10 \%$ or greater error in approximately $10 \%$ of the studies, degrading the reliability of large vessel flow, requiring careful consideration of correction methods. 


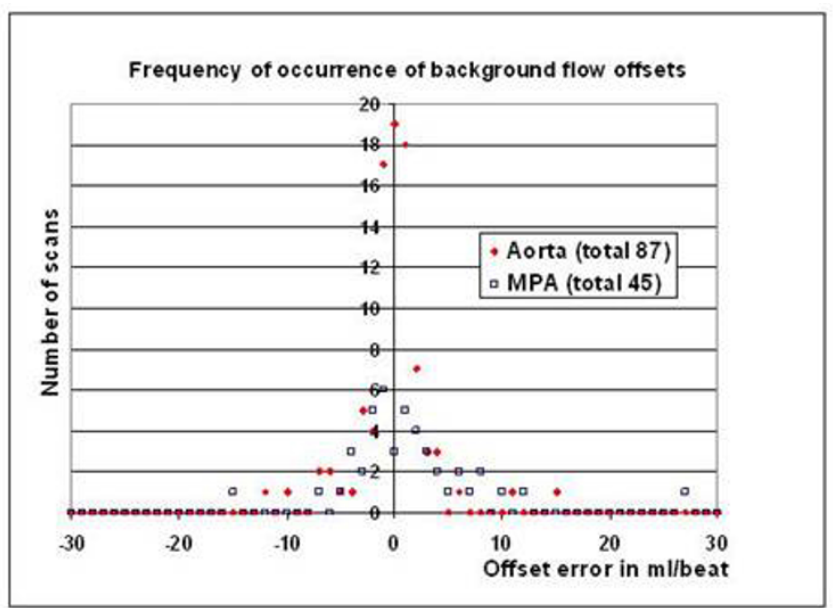

Figure I

Publish with Biomed Central and every scientist can read your work free of charge

"BioMed Central will be the most significant development for disseminating the results of biomedical research in our lifetime. " Sir Paul Nurse, Cancer Research UK

Your research papers will be:

- available free of charge to the entire biomedical community

- peer reviewed and published immediately upon acceptance

- cited in PubMed and archived on PubMed Central

- yours - you keep the copyright 